\title{
What are the implications of the Paris Agreement for inequality?
}

\section{Caroline Zimm $^{1, *}$, Nebojsa Nakicenovic ${ }^{2}$}

1 International Institute for Applied Systems Analysis (IIASA); zimmc@iiasa.ac.at;

2 International Institute for Applied Systems Analysis (IIASA); naki@iiasa.ac.at;

* Correspondence: zimmc@iiasa.ac.at; Tel.: +43 2236/807 274, ORCID: https://orcid.org/0000-0001-5603-1015

DOI: https://www.tandfonline.com/doi/full/10.1080/14693062.2019.1581048

Acknowledgements: The work was supported by the International Institute for Applied Systems Analysis (IIASA) within The World in 2050 (TWI2050) initiative. The authors would like to thank Narasimha Rao for valuable discussions during the development of the manuscript.

\section{Abstract}

Climate change is a major planetary challenge. Its consequences threaten the provision of Earth-system services and sustainable development. The impacts and the capacities to adapt vary across countries and different incomes, as do the historical and current emissions of greenhouse gases (GHGs) and thus the responsibility for anthropogenic climate change. This has generated a complex debate about the inequities inherent in the climate challenge. This paper analyses the potential implications of the full implementation of the first round of Nationally Determined Contributions (NDCs) of the Paris Agreement for countries' per capita GHG emissions and the related inequality measures of the Gini coefficient and Lorenz curve. The distribution of annual and cumulative GHG emissions per capita for selected years and periods pre- and post-Paris of two NDC scenarios are assessed to derive implications for desired increases in ambition levels. The results show that the NDCs, while not meeting the Paris targets to limit temperature increase if levels of ambition remain the same after 2030, lead towards a more equitable future in terms of GHG emissions.

\section{Policy Insights}

- The NDCs lead to decreases in GHG emissions inequality (lower Gini coefficients) across countries compared to 1990. 
- The rate of decrease in inequality 2016-2030 slows down compared to $1990-2015$.

- Conditional pledges in the NDCs lead to smaller reductions in GHG emissions inequality than unconditional pledges.

- This highlights tension between the pursuit of decreasing GHG emissions inequality and the ambition to lower overall global GHG emissions.

Keywords: nationally determined contributions; Gini coefficient; Lorenz curves; Paris Agreement; climate equity; per capita GHG emissions

\section{Introduction}

Climate change and its consequences threaten human development and involve inequities $^{1}$ : The inequities are huge, in terms of historical and current contributions to global greenhouse gas (GHG) emissions, and regarding how countries and people are impacted by the resulting climate change and their capacities to adapt (Roberts, 2009; Roberts and Parks, 2007a). Climate change is hence an ethical issue (Gardiner, 2004) that touches upon balancing interests across countries, generations and species with 'ethical considerations of justice, rights, welfare, virtue, political legitimacy, community and humanity's relationship to nature $[\ldots]$ at the heart of the policy decisions to be made' (Gardiner, 2016). This has generated a debate about historical responsibility of developed countries and the need for sustainable growth pathways for developing countries (Gupta, 2012).

The 1992 UN Framework Convention on Climate Change (UNFCCC) addressed equity through establishing common but differentiated responsibilities and respective

\footnotetext{
${ }^{1}$ Note: This paper differentiates between the concepts of equity and equality as follows: Equity entails a distribution of resources (or burden as in the case at hand) in a manner that reflects fairness, cognizant of the challenges to define fairness. Equality entails the equal distribution of resources, meaning that every entity (e.g. person) gets the exact same allocation.
} 
capabilities as a basic principle, and required developed countries to take the lead in curbing emissions (UN, 1992, Article 3, 4.2(a) and (b)). The 1997 Kyoto Protocol implemented legally-binding commitments to reduce or limit GHG emissions of historically high emitting countries (UNFCCC, 1997, Article 3). The Protocol has had limited effect as some major emitters did not ratify it (United States), did not join the second commitment period (Russia and Japan) or withdrew from it (Canada). Diverse perspectives on differentiated responsibilities between developed and developing countries have long paralyzed the climate negotiations process (Pauw et al., 2014; Rajamani, 2013; Roberts and Parks, 2007b), which entered a new epoch with the adoption and entry into force of the 2015 Paris Agreement (Höhne et al., 2017; Rajamani, 2016; Slaughter, 2015).

The Paris Agreement (UNFCCC, 2015a) follows a bottom-up approach by relying on voluntary (Intended) Nationally Determined Contributions ((I)NDCs) which lay out the climate action plans of individual countries to contribute to the globally agreed target to limit global warming to 'well below' two degrees Celsius, and pursue efforts towards a 1.5 degree Celsius limit. Klinsky et al. (2017) argue that the agreement lacks clear equity definitions and declarations, and that it gives way to a post-equity era with focus on voluntary self-determined national contributions regardless of historical responsibility. Other scholars see national determination and differentiation as levers for equity that made the agreement possible (Rajamani, 2016; Voigt and Ferreira, 2016). Pauw et al. (2018) note that countries were provided with the flexibility to voice their priorities in the INDCs. This broke apart the dichotomy between developed and developing countries, indicated by close to universal submission.

Equity and justice are central to climate policy making and are not only normative but also positive in that the likelihood and effectiveness of reaching, 
maintaining and implementing an agreement is higher if parties consider it as equitable and fair (Klinsky et al., 2017; Fleurbaey et al., 2014; Victor, 2007; Rose and Kverndokk, 1999). The ambition level of an agreement has also been related to its equity dimension (Winkler et al., 2018; Athanasiou, 2017). Höhne et al. (2017) argue that a concern about equity was maybe one reason for the conservative nature of the INDCs. Upon ratification of the Paris Agreement, most countries' INDCs turned into the first round of Nationally Determined Contributions (NDCs) with some later additions. We will use the term NDCs from now on in this paper.

The submitted NDCs are estimated to lead to emission levels that are not consistent with the Paris Agreement targets to limit temperature increase, if levels of ambition remain the same after 2030 (UNFCCC, 2015b, para 39), with a projected global average temperature increase of $2 \cdot 6-3.1^{\circ} \mathrm{C}$ above pre-industrial levels (Rogelj et al., 2016). Still, they represent a new playing field and opportunity for climate policy (Chancel and Piketty, 2015). Through their bottom-up nature, they provide an indication of each country's ambitions. Ideally, the NDCs should represent relative national fair shares needed to meet the global temperature goals. The relevant guidance notes that they 'may include [...] how the Party considers that its intended nationally determined contribution is fair and ambitious [...]' (UNFCCC 2014, para 14). There is, however, no consensus among countries on how to measure fair shares, let alone how to define them, which will be looked into in more detail in the next section.

The Paris Agreement is also linked to the United Nations' 2030 Agenda on Sustainable Development through Sustainable Development Goal (SDG) 13 on climate action, for which the UNFCCC is recognized as primary responsible entity (UN GA, 2015). The 2030 Agenda calls for a more equitable world, aiming to reduce inequalities within and between countries (foremost SDG 1 on poverty eradication and SDG 10 on 
reducing inequalities) and improving human development while reducing environmental impacts. It provides a broad narrative for human development which ideally guides the NDCs to harness synergies and to avoid any negative trade-offs with other SDGs, going beyond a climate-only perspective (see Janetschek et al. (in prep) for a detailed assessment of the interlinkages between NDCs and SDGs).

Distributional implications (Winkler et al., 2018) are likely to inform ambition levels in the next round of NDCs, and will be an important theme during the global stocktake in 2023 which will take place 'in the light of equity' (UNFCCC, 2015a, Article 14, para 1 and 2). The facilitative Talanoa Dialogue informing the 2019 stocktake on pre-2020 ambition concluded in 2018 that 'Ensuring a just transition will be key to achieving the goals of the Paris Agreement' (UNFCCC 2018).

Against this background, this paper aims to assess the potential implications of the full implementation of NDCs on inequality in countries' per capita GHG emissions. The next section will discuss the issue of defining a fair share in climate change mitigation, before presenting the methods employed in this study. Results are then discussed, followed by limitations and conclusions.

\section{What is a fair share?}

Roberts and Parks (2007b) identify a wide consensus on what is fair as crucial for successfully mastering the climate change challenge. What is fair and where the temporal, spatial or system boundary is set is a normative, complex and unresolved debate on choosing criteria to define equity. This debate includes perspectives on emissions budgets and mitigation efforts (see for example Holz et al. (2018), Peters et al. (2015), Raupach et al. (2014) and Baer (2002)) as well as support for adaptation to climate change such as financing, technology transfer or capacity building (Klinsky et al., 2017; Dellink et al., 2009; Roberts, 2009), and concerns related to future 
development (Kartha et al., 2014; Baer et al., 2008). ${ }^{2}$ Several influencing principles for theoretical burden sharing regimes of GHG emissions (and combinations thereof), relating predominantly to climate change mitigation but partly also to adaptation, have been identified in the literature (Kartha et al., 2018; Fleurbaey et al., 2014; Höhne et al., 2014), favouring different country groups (depending on emission level, economic output, population size, etc.) to varying degrees: responsibility (historical emissions); capability (ability to pay); right to development; equality; and types of emissions (e.g. survival versus luxury, land-use emissions). Further applied criteria with implications for equity include cost-effectiveness, methods of emissions accounting ${ }^{3}$, and prioritization of action (e.g. eradication of poverty).

While there are arguments for each of these entry points to equity, this paper follows an approach along the principle of equality based on equal per capita emissions. Baer (2002) and Starkey (2009) argue that as the atmosphere is a global commons essential to everyone's well-being, this demands approaches to equity that are based on equal per capita allocations. In line with that notion, Fleurbaey et al. (2014) call equal per capita emissions 'the most straightforward resource-sharing approach'. While such egalitarian approaches might seem intuitive, they have been deemed inefficient and are contested in political climate discussions (Roberts and Parks, 2007b). Most importantly

\footnotetext{
${ }^{2}$ Considerations relevant to equity and equality related to climate change as discussed in this paper should not be confused with considerations relevant to economic inequality, where policy implications may be different.

${ }^{3}$ Steininger et al. (2016) show that every emissions accounting system has strong implications for equity. This analysis follows the production based accounting method, which is the dominating approach in climate policy, also followed by the UNFCCC. As most (I)NDCs include all Kyoto gases in various sectors, and as the timeframe of analysis is short and high urgency exists with regards to climate change mitigation, the analysis covers also non- $\mathrm{CO}_{2}$ gases, weighted according to their global warming potential from IPCC (2007) Total of GHG emissions are given in $\mathrm{CO}_{2}$ equivalents $\left(\mathrm{tCO}_{2} \mathrm{e}\right)$ Most (I)NDCs span the period till 2030 but not all. For harmonization purposes, they were translated to 2030-GHG emission - for details see Meinshausen and Alexander (2017). In many cases, the interpretation of the (I)NDCs comes with a range of caveats and uncertainties in future emission levels, as also raised by Meinshausen and Alexander (2017). This analysis provides two different scenarios to accommodate for this. For a thorough assessment of the uncertainties of the (I)NDCs see Rogelj et al. (2017).
} 
for this analysis though, annual per capita emissions feature in 60 NDCs, thus being the second most widely used equity indicator in the NDCs in relation to mitigation, after ' $a$ small share of global emissions' (Winkler et al., 2018). This shows that per capita emissions is an indicator that policymakers use in negotiations and are familiar with, highlighting its policy relevance.

\section{Methods}

This analysis assesses the equality implications of the NDCs in terms of the distribution of annual and cumulative per capita GHG emissions via Gini coefficients and Lorenz curves. It provides a comparison with the time before Paris, adding a new element to the literature on the NDCs.

The Gini coefficient and Lorenz curve (Lorenz, 1905) are a measure of distribution of goods between population groups, foremost income. They have also been applied to other domains such as health (Williams and Cookson, 2000), education (Sauer and Zagler, 2014; Vinod et al., 2001), technology (Bento 2017, Hilbert, 2016), human environmental impact and resource use (Malakar and Mishra, 2017; TeixidóFigueras et al., 2016; Druckman and Jackson, 2008) as well as $\mathrm{CO}_{2}$ and other GHG emissions (Pan et al., 2014a; Pan et al., 2014b; Groot, 2010; Heil and Wodon, 1997). Teng et al. (2011) extended this approach to cumulative historical carbon emissions, reflecting historical responsibilities of developed countries. Pan et al. (2015) analyzed the Gini coefficient for all Kyoto GHG gases for a wide range of effort-sharing schemes for the period 1850-2050 (Pan et al., 2015).

The Gini coefficient and Lorenz curve are well known and are practical communication tools (see Figure 1). The horizontal axis shows the cumulative population of countries ranked in ascending order of their average per capita GHG emissions. The vertical axis shows the respective cumulative GHG emissions. If per 
capita GHG emissions were distributed equally worldwide, the Lorenz curve would match the 45-degree line (line of equality), and the Gini coefficient would be 0 (perfect equality). The Gini coefficient is the fraction of the area between the line of equality and the Lorenz curve (the dividend) over the total area under the line of equality (the divisor). Its maximum value is 1 .

The assessments of the NDCs and equity tend to look into the long-term future and assess how they perform under different climate change scenarios, allocating remaining carbon budgets top-down, reflecting diverse effort-sharing regimes (e.g. Climate Action Tracker, 2018; Holz et al., 2018; Pan et al., 2017; Robiou du Pont et al., 2016; Athanasiou et al., 2014). While they provide some insights into a part of the aspects related to the complexity of the equity discussion (see above), their results are often complicated to communicate to policymakers and also touch upon approaches not reflected in the NDCs. They also tend to focus on a select range of countries, large emitters or aggregated regions. In contrast, this analysis takes a bottom-up approach, covering all national pledges based on one of the most widely used indicators. It aims to create a better understanding about the NDCs that could be useful for their revision.

To our knowledge, this is the first assessment of the Gini coefficients and Lorenz curves of the NDCs covering all countries. This analysis uses GHG emission data for the NDCs (excluding LULUCF) that is publicly available from the AustralianGerman Climate and Energy College (Meinshausen and Alexander, 2017). The data cover 195 countries, representing roughly $99 \%$ of global population and two scenarios of NDCs. These take into account that the majority of countries submitted conditional mitigation pledges subject to the availability of support (in terms of finance, capacity building or technology transfer) by other countries, as stated in their NDCs, as well as unconditional pledges they aim to follow through irrespective of outside assistance. 
More than 100 of the submitted NDC mitigation pledges are partly or fully conditional (Pauw et al., 2016). The conditional pledges are more ambitious. In the following analysis, the high ambition level scenario 'NDC-cond' includes conditional contributions (partly subject to available outside financial or technical support) while the low ambition case 'NDC-uncond' represents countries' unconditional contributions only. The NDC-uncond scenario would translate to temperature increases of around $3.2^{\circ} \mathrm{C}$ above pre-industrial levels by 2100 , and the NDC-cond scenario to about $3.0^{\circ} \mathrm{C}$, assuming that similar policies continue throughout the $21^{\text {st }}$ century, while current policies would lead to a temperature increase of around $3.4^{\circ} \mathrm{C}$ (UNEP, 2017). Gini coefficients and Lorenz curves are derived for annual and cumulative GHG emissions per capita for selected years and time periods pre- and post-Paris.

\section{Results}

Figure 1, panel (a) shows the Lorenz curves of annual per capita emissions for selected years pre- and post-Paris. Annual emissions are chosen to highlight the pathway effect of the NDCs on the way to a more equitable and sustainable future. Panel (b) shows the Gini coefficient and total global annual GHG emissions over time. The Gini coefficient improved by around 10\%, from 1990 (0.547) to $2000(0.497)$ and again to 2015 (0.442), while global emissions were increasing. The historical changes affecting a broad share of the population in the middle and higher range of emissions (between $30 \%$ and $90 \%$ of cumulative population) are mainly driven by China. Looking at 2030, the NDC-cond scenario (0.436) practially keeps the 2015 equality level (0.442), though at a lower overall emission level. The NDC-uncond scenario (0.401) is more equal, continuing the converging trend as developing countries' emissions increase. In the NDC-cond scenario with its conditional pledges, developing countries contribute more to mitigation (lower emissions) than developed countries, provided that 
they receive support in implementing the conditional pledges. This leads to a levellingoff in Gini coefficient improvements and can be seen in the gap between the two Lorenz curves, NDC-cond and NDC-uncond.

Note that all Lorenz curves move closer to the line of equality from 1990 to 2030. The lowest $20 \%$ of population keeps the same share of global emissions.

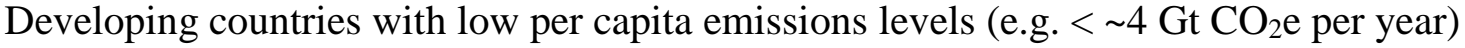
make up $\sim 50 \%$ of the population in $2030.30 \%$ of the population show per capita emission levels of above $10 \mathrm{Gt} \mathrm{CO}_{2} \mathrm{e}$ per year.
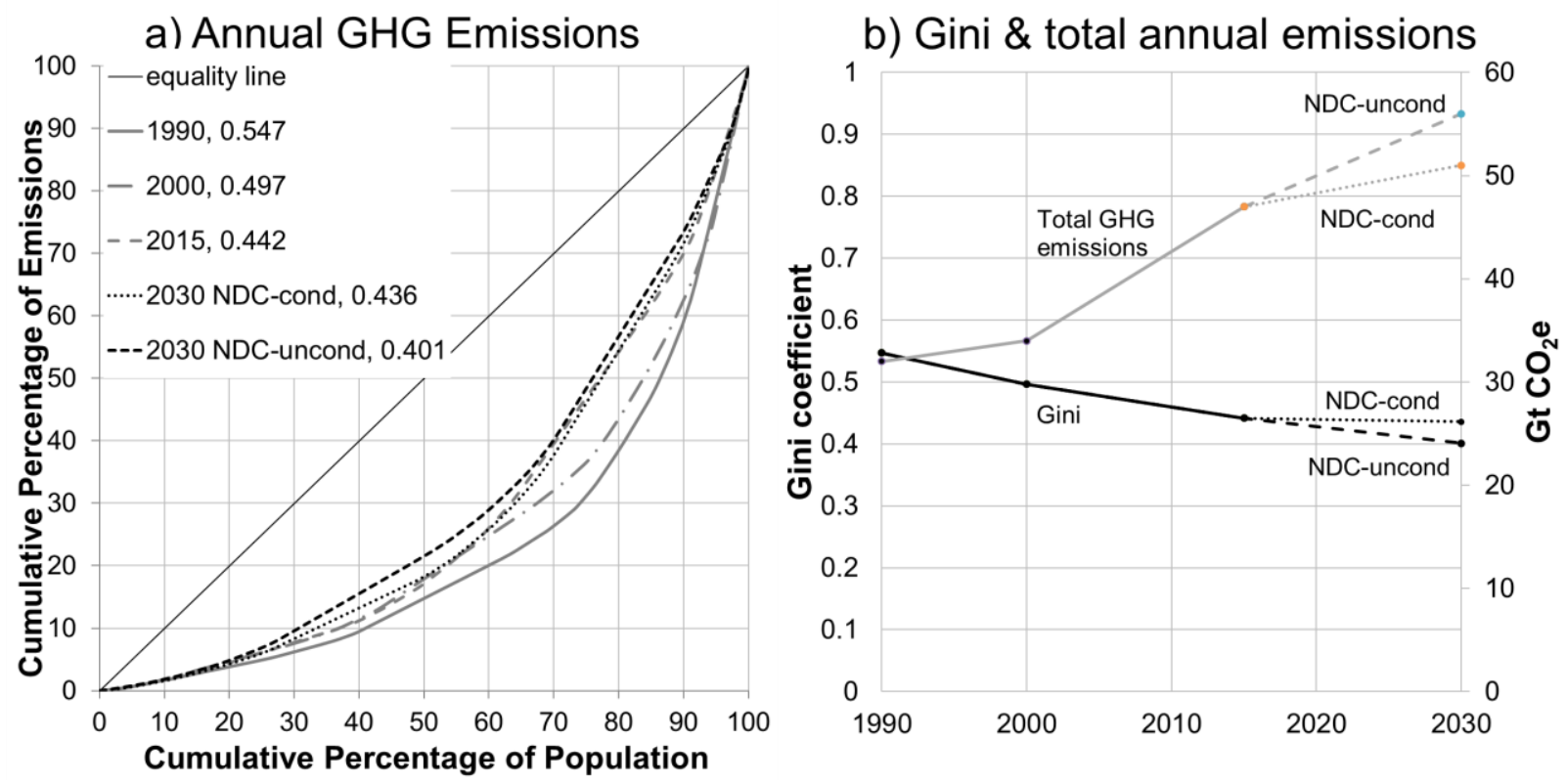

Figure 1: a) Lorenz curves and Gini coefficients for annual GHG emissions per capita pre- and post-Paris. Inequality has been decreasing over the years, with future reductions in the NDC scenarios slowing down the rate of decrease. b) Gini coefficients for annual GHG emissions per capita (black) and total global GHG emissions (grey) pre- and post-Paris. While GHG emission levels are increasing, inequality is decreasing. The conditional pledges (NDC-cond) lead to lower GHG emissions while stabilizing the inequality level. 
Global average annual per capita GHG emissions as based on data included in the NDCs range between 6.1 (NDC-cond) and 6.7 (NDC-uncond) $\mathrm{tCO}_{2 \mathrm{e}} /$ capita in 2030, with a 2015 level of around $6.5 \mathrm{tCO}_{2 \mathrm{e}} /$ capita, and countries slowly converging (Figure 2), with some exceptions (e.g. Russia and China). The global median is expected to decrease from currently 5.2 to 3.6 (NDCs-cond) and $4.1 \mathrm{tCO}_{2 \mathrm{e}} /$ capita (NDC-uncond) (Meinshausen and Alexander, 2017).

\section{Annual per capita $\mathrm{Gt} \mathrm{CO}_{2} \mathrm{e}$}

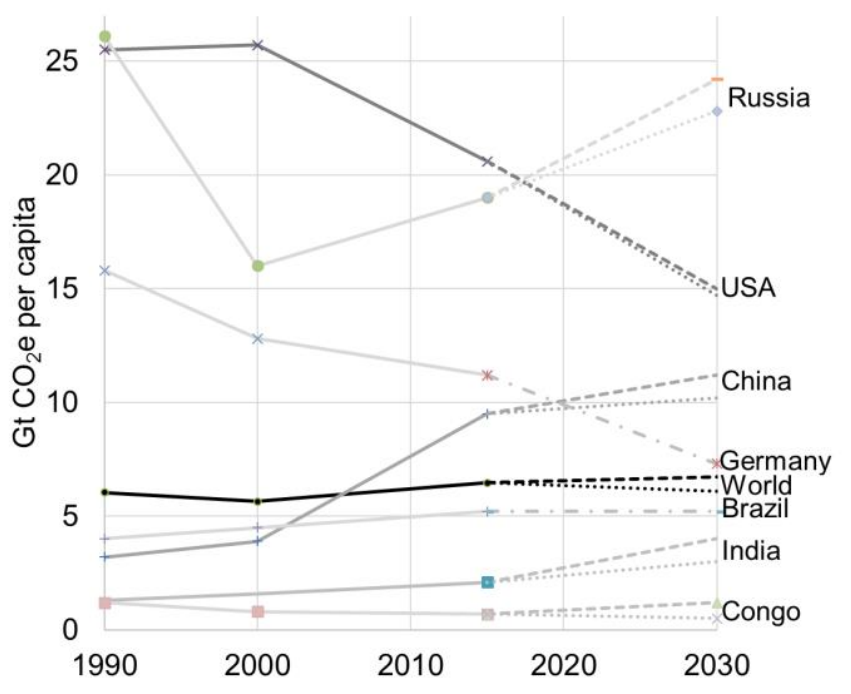

Figure 2: Annual per capita GHG emissions and world average for selected countries pre- and post- Paris, NDC-uncond (dashed) and NDC-cond (dotted). Several countries change positions in NDC-scenarios.

Figure 3 assesses the distributional effect of cumulative GHG emissions as implied by the NDCs up to 2030 compared to the 25 years of climate negotiations before the Paris Agreement since 1990. This assesses the overall equality implications of the first round of NDCs. The more ambitious NDC-cond scenario has a higher Gini coefficient (0.440) - and is thus more unequal - than the NDC-uncond scenario (0.417), while both of them are lower compared to the years before Paris (0.478). From a climate 
mitigation perspective, the scenario with the higher Gini coefficient would be preferred as it leads to lower overall GHG emissions.

A large share of the difference in the two scenarios as shown in Figure 3 can be attributed to India, while the majority of the shift closer to the line of equality of the Lorenz curves pre- to post-Paris is related to China. Example countries are highlighted in panel (b) of Figure 3, with some changing positions: Russia overtakes the United States for example, and China moves up the Lorenz curve while Germany moves down, reflecting the changes in per capita GHG emissions as shown in Figure 2. Note that in the cumulative case the Lorenz curves are moving closer to the line of equality with a kink at $60 \%$ of the population representing roughly $25-26 \%$ of emissions before and after Paris. This is due to the larger spread in cumulative emissions compared to annual emissions. The $25 \%$ of the population with the lowest per capita GHG emissions keeps its share in global emissions.

a) Cumulative GHG Emissions

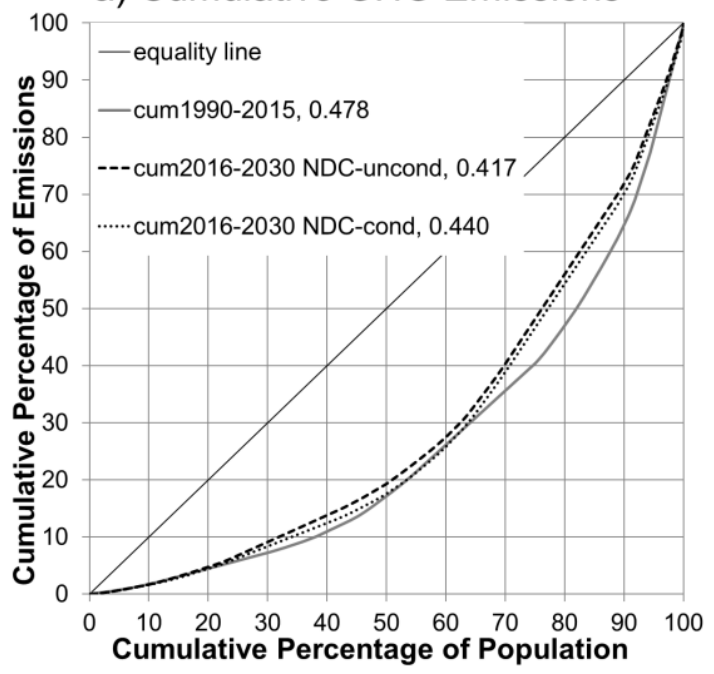

b) Country Examples

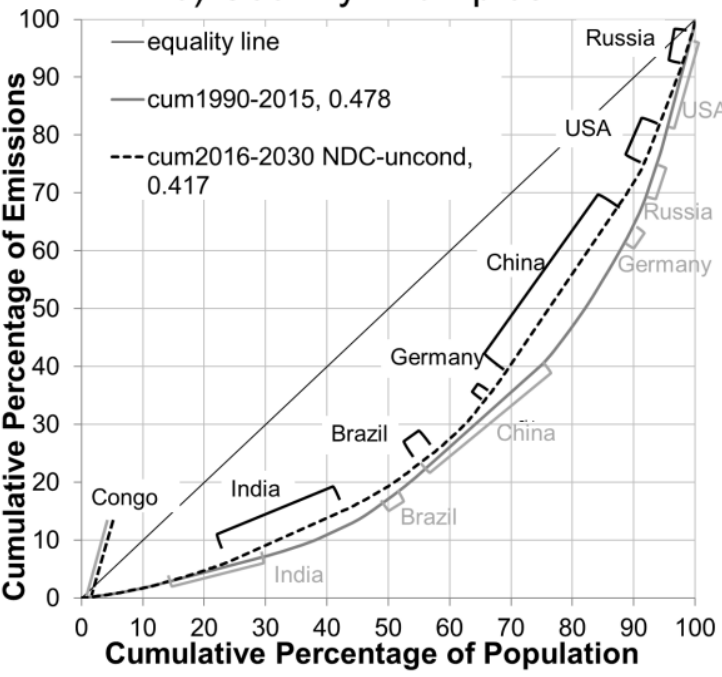

Figure 3: Lorenz curves and Gini coefficients for cumulative GHG emissions per capita pre- and post-Paris. Panel b) highlights select country examples and their rank on the Lorenz curve pre-Paris and for one of the NDC-scenarios post-Paris. Several countries 
change positions. China's move up the Lorenz curve contributes largely to the reductions in inequality between pre- and post-Paris.

\section{Limitations}

There are a number of caveats regarding the results. One issue is related to the choice in measure, as the Gini coefficient and Lorenz curve are independent of the total global GHG emission level. An improvement in equality can thus be achieved by low emitters increasing but also by high emitters reducing their emissions. So far and up to a certain level, GHG emissions have been related to human development (Rao et al., 2014). This is changing as humanity is entering a phase where low carbon trajectories might be vital - maybe even a competitive advantage - for development. It is thus necessary to keep the global emission level in mind.

At the same time, the underlying indicator of per capita GHG emissions, as used in this paper and in many of the NDCs to track fair shares, cannot capture the complexity of the equity debate (see above) as a whole. The debate calls for careful interpretation bearing in mind inequities arising from the impacts of climate change, historical responsibility, differentiated adaptive and mitigative capacity, the right to development, differences in emissions types or that conditional pledges of developing countries are subject to, inter alia, (financial) support from developed countries. Any difference in mitigation level due to (partly) conditional elements in the NDC-scenarios achieved through outside support (financial, capacity building or technology transfer) is, in this analysis and according to current international GHG accounting practices, attributed to the country pledging the conditional NDCs (see Pauw et al. (in prep) for a detailed assessment of conditional NDCs). 
This paper looks at differences across countries as countries are the entities negotiating global climate policies. However, large discrepancies between socioeconomic groups within countries exist and are increasing (Chancel and Piketty, 2015; Rao, 2014). It is estimated that within-country inequality explains $50 \%$ of global GHG emission inequality (Chancel and Piketty, 2015). Average country values thus underestimate the range of inequality. A Lorenz curve ranking all individuals of the world according to their per capita GHG emissions showing global inequality would be much more skewed than the Lorenz curves presented here.

\section{Conclusion}

This analysis assesses the aggregate equality dimension of a full implementation of the first round of NDCs by deriving the Gini coefficients and Lorenz curves for select years and time periods pre- and post-Paris. The results show that the NDCs lead to reduced inequality in terms of per capita GHG emissions compared to the time before the Paris Agreement, while the rate of decrease slows down. The NDCs of developed countries mainly pursue the pre-Paris equality status. The higher ambition level of developing countries as expressed in their conditional pledges (NDC-cond) would hamper a further decrease in terms of GHG emissions inequality as measured by the Gini coefficient, while leading to lower global GHG emissions. The implications of outside support for developing countries on their conditional ambition levels needs to be kept in mind when interpreting the Gini coefficients and Lorenz curves. The low ambition scenario of unconditional pledges (NDC-uncond) leads to greater GHG emissions equality, as developing countries catch up more quickly with developed countries in terms of per capita GHG emission levels.

This leads to a potential tension between the pursuit of decreasing GHG emissions inequality and the ambition to lower overall global GHG emissions. Fairness 
and ambition should not work against each other but go hand in hand. Support for developing countries by developed countries should be made more attractive in the next round of NDCs. Similar to existing mechanisms (e.g. Clean Development Mechanism) one option to do so would be to highlight the (financial) support made available to realize the conditional pledges and related mitigation effects in developing countries in the NDCs of developed countries. This could be taken up during the global stocktake. To contribute to higher overall mitigation ambition, countries can ratchet up mitigation efforts domestically, invest in mitigation activities abroad or combine the two approaches to serve national conditions.

Increased ambition in terms of mitigation and (financial) support of high emitters for developing countries will raise the chances of reaching the Paris target to limit temperature increase and improve perceived fairness at the same time. This will also strengthen developing countries in implementing and enhancing their conditional

pledges (see Roeser al. (in prep) for a detailed assessment of stakeholders' perception of needed support for NDC implementation). There is a risk that strongly needed rises in ambition, such as conditional pledges or higher mitigation levels of front runners are not realized if countries feel their pledged contributions are not fairly matched or supported (financially) by others (Höhne et al. 2017; PAuw et al (in prep)). This is crucial as an overall higher mitigation level is needed to achieve the Paris target to limit temperature increase.

\section{Declaration of interest statement}

No conflict of interest. 


\section{References}

Athanasiou, T. (2017). Climate justice as the post-Trump slingshot. Retrieved from http://www.ecoequity.org/key-posts/

Baer, P. (2002). Equity, greenhouse gas emissions, and global common resources. In $\mathrm{S}$. Schneider, A. Rosencranz, \& J. Niles (Eds.), Climate change policy: A survey (pp. 393-408). Washington, DC: Island Press.

Baer, P., Fieldman, G., Athanasiou, T., \& Kartha, S. (2008). Greenhouse development rights: Towards an equitable framework for global climate policy. Cambridge Review of International Affairs, 21, 649-669. doi: 10.1080/09557570802453050

Chancel, L., \& Piketty, T. (2015). Carbon and inequality: From Kyoto to Paris trends in the global inequality of carbon emissions (1998-2013) \& prospects for an equitable adaptation fund. Paris School of Economics.

Climate Action Tracker. (2018). Ranking countries: Retrieved from https://climateactiontracker.org/countries/

Dellink, R., Elzen, M. D., Aiking, H., Bergsma, E., Berkhout, F., Dekker, T., \& Gupta, J. (2009). Sharing the burden of financing adaptation to climate change. Global Environmental Change, 19, 411-421. doi: 10.1016/j.gloenvcha.2009.07.009

Druckman, A., \& Jackson, T. (2008). Measuring resource inequalities: The concepts and methodology for an area-based Gini coefficient. Ecological Economics, 65, 242-252. doi: 10.1016/j.ecolecon.2007.12.013

Fleurbaey, M., Kartha, S., Bolwig, S., Chee, Y. L., Chen, Y., Corbera, E., ... Sagar, A. D. (2014). Sustainable development and equity. In O. Edenhofer, R. Pichs-Madruga, Y. Sokona, E. Farahani, S. Kadner, K. Seyboth, ... J. C. Minx (Eds.), Climate change 2014: Mitigation of climate change. Contribution of working group III to the fifth assessment report of the intergovernmental panel on climate change. Cambridge: Cambridge University Press.

Gardiner, S. (2016, January 9). Why climate change is an ethical problem. The Washington Post.

Gardiner, S. M. (2004). Ethics and global climate change. Ethics, 114, 555-600. doi: $10.1086 / 382247$

Groot, L. (2010). Carbon Lorenz curves. Resource and Energy Economics, 32, 45-64. doi: 10.1016/j.reseneeco.2009.07.001

Gupta, J. (2012). Negotiating challenges and climate change. Climate Policy, 12, 630 644. doi: 10.1080/14693062.2012.693392

Heil, M. T., \& Wodon, Q. T. (1997). Inequality in CO2 emissions between poor and rich countries. The Journal of Environment \& Development, 6, 426-452. doi: 10.1177/107049659700600404

Hilbert, M. (2016). The bad news is that the digital access divide is here to stay: Domestically installed bandwidths among 172 countries for 1986-2014. Telecommunications Policy, 40, 567-581. doi: 10.1016/j.telpol.2016.01.006

Höhne, N., den Elzen, M., \& Escalante, D. (2014). Regional GHG reduction targets based on effort sharing: A comparison of studies. Climate Policy, 14, 122-147. doi: 10.1080/14693062.2014.849452

Höhne, N., Kuramochi, T., Warnecke, C., Röser, F., Fekete, H., Hagemann, M., ... Gonzales, S. (2017). The Paris Agreement: Resolving the inconsistency between global goals and national contributions. Climate Policy, 17, 16-32. doi: 10.1080/14693062.2016.1218320

Holz, C., Kartha, S., \& Athanasiou, T. (2018). Fairly sharing 1.5: National fair shares of a $1.5{ }^{\circ} \mathrm{C}$-compliant global mitigation effort. International Environmental 
Agreements: Politics, Law and Economics, 18, 117-134. doi: 10.1007/s10784-0179371-z

IPCC. (2007). Climate change 2007: The physical science basis. (Contribution of Working Group I to the Fourth Assessment Report of the Intergovernmental Panel on Climate Change). Cambridge, UK: Cambridge University Press.

Janetschek et al. (in preparation). Synergies and trade-offs with the 2030 Agenda. Manuscript in preparation.

Kartha, S., Athanasiou, T., \& Baer, P. (2014). Fair shares' and intended nationally determined contributions: What can we learn from an equity review?. Stockholm: Stockholm Environment Institute. SEI discussion brief.

Kartha, S., Athanasiou, T., Caney, S., Cripps, E., Dooley, K., Dubash, N. K., ... Winkler, H. (2018). Cascading biases against poorer countries. Nature Climate Change, 8, 348-349. doi: 10.1038/s41558-018-0152-7

Klinsky, S., Roberts, T., Huq, S., Okereke, C., Newell, P., Dauvergne, P., ... Bauer, S. (2017). Why equity is fundamental in climate change policy research. Global Environmental Change, 44, 170-173. doi: 10.1016/j.gloenvcha.2016.08.002

Lorenz, M. O. (1905). Methods of measuring the concentration of wealth. Publications of the American Statistical Association, 9, 209-219. doi: 10.2307/2276207

Malakar, K., \& Mishra, T. (2017). Application of Gini, Theil and Concentration indices for assessing water use inequality. International Journal of Social Economics, 44, 1335-1347. doi: 10.1108/IJSE-01-2016-0017

Meinshausen, M., \& Alexander, R. (2017). NDC \& INDC Factsheets. The University of Melbourne.

Pan, X. Z., den Elzen, M., Höhne, N., Teng, F., \& Wang, L. (2017). Exploring fair and ambitious mitigation contributions under the Paris Agreement goals. Environmental Science \& Policy, 74, 49-56. doi: 10.1016/j.envsci.2017.04.020

Pan, X., Teng, F., Ha, Y., \& Wang, G. (2014a). Equitable access to sustainable development: Based on the comparative study of carbon emission rights allocation schemes. Applied Energy, 130, 632-640. doi: 10.1016/j.apenergy.2014.03.072

Pan, X. Z., Teng, F., Tian, Y. L., \& Wang, G. H. (2015). Countries' emission allowances towards the low-carbon world: A consistent study. Applied Energy, 155, 218-228. doi: 10.1016/j.apenergy.2015.06.011

Pan, X., Teng, F., \& Wang, G. (2014b). A comparison of carbon allocation schemes: On the equity-efficiency tradeoff. Energy, 74, 222-229. doi: 10.1016/j.energy.2014.05.109

Pauw, W. P., Bauer, S., Richerzhagen, C., Brandi, C., \& Schmole, H. (2014). Different perspectives on differentiated responsibilities. A state-of-the-art review of the notion of common but differentiated responsibilities in international negotiations. (Discussion Paper). Bonn: Deutsches Institut für Entwicklungspolitik.

Pauw, W. P., Cassanmagnano, D., Mbeva, K., Hein, J., Guarin, A., Brandi, C., ... Muhammad, D. (2016). NDC Explorer. German Development Institute / Deutsches Institut für Entwicklungspolitik (DIE), African Centre for Technology Studies (ACTS), Stockholm Environment Institute (SEI).

Pauw, W. P., Klein, R. J. T., Mbeva, K., Dzebo, A., Cassanmagnago, D., \& Rudloff, A. (2018). Beyond headline mitigation numbers: We need more transparent and comparable NDCs to achieve the Paris Agreement on climate change. Climatic Change, 147, 23-29. doi: 10.1007/s10584-017-2122-x

Pauw et al. (in preparation). Whose ambition? Opportunities and weaknesses of conditional contributions. Manuscript in preparation. 
Peters, G. P., Andrew, R. M., Solomon, S., \& Friedlingstein, P. (2015). Measuring a fair and ambitious climate agreement using cumulative emissions. Environmental Research Letters, 10, 105004. doi: 10.1088/1748-9326/10/10/105004

Rajamani, L. (2013). Differentiation in the emerging climate regime. Theoretical Inquiries in Law, 14, 151-172. doi: 10.1515/til-2013-009

Rajamani, L. (2016). Ambition and differentiation in the 2015 Paris Agreement: Interpretative possibilities and underlying politics. International and Comparative Law Quarterly, 65, 493-514. doi: 10.1017/S0020589316000130

Rao, N. D. (2014). International and intranational equity in sharing climate change mitigation burdens. International Environmental Agreements: Politics, Law and Economics, 14, 129-146. doi: 10.1007/s10784-013-9212-7

Rao, N. D., Riahi, K., \& Grubler, A. (2014). Climate impacts of poverty eradication. Nature Climate Change, 4, 749-751. doi: 10.1038/nclimate2340

Raupach, M. R., Davis, S. J., Peters, G. P., Andrew, R. M., Canadell, J. G., Ciais, P., ... Le Quere, C. (2014). Sharing a quota on cumulative carbon emissions. Nature Climate Change, 4, 873-879. doi: 10.1038/nclimate2384

Roberts, J. T. (2009). The international dimension of climate justice and the need for international adaptation funding. Environmental Justice, 2, 185-190. doi: 10.1089/env.2009.0029

Roberts, J. T., \& Parks, B. C. (2007a). A climate of injustice: Global inequality. Northsouth politics, and climate policy. Cambridge, MA: Institute of Technology.

Roberts, J. T., \& Parks, B. C. (2007b). Fueling injustice: Globalization, ecologically unequal exchange and climate change. Globalizations, 4, 193-210. doi: 10.1080/14747730701345218

Robiou du Pont, Y., Jeffery, M., Gütschow, J., Rogelj, J., Christoff, P., \& Meinshausen, M. (2016). Equitable mitigation to achieve the Paris Agreement goals. Nature Climate Change, 7, 38-43. doi: 10.1038/nclimate3186

Roeser, F., Hoehne, N., \& Day, T. (in preparation). Making climate action more transparent and ambitious: lessons learned from the first Nationally Determined Contributions (NDCs). Manuscript in preparation.

Rogelj, J., den Elzen, M., Höhne, N., Fransen, T., Fekete, H., Winkler, H., ... Meinshausen, M. (2016). Paris Agreement climate proposals need a boost to keep warming well below $2^{\circ} \mathrm{C}$. Nature, 534, 631-639. doi: 10.1038/nature18307

Rogelj, J., Fricko, O., Meinshausen, M., Krey, V., Zilliacus, J. J. J., \& Riahi, K. (2017). Understanding the origin of Paris Agreement emission uncertainties. Nature Communications, 8, 15748. doi: 10.1038/ncomms 15748

Rose, A., \& Kverndokk, S. (1999). Equity in environmental policy with an application to global warming. In J. Van Den Bergh (Ed.), Handbook of environmental and resource Economics (pp. 380). Cheltenham: Edward Elgar.

Sauer, P., \& Zagler, M. (2014). (In)equality in education and economic development. Review of Income and Wealth, 60, S353-S379. doi: 10.1111/roiw.12142

Slaughter, A.-M. (2015). The Paris approach to global governance [Online]. Project Syndicate. Retrieved from https://www.project-syndicate.org/commentary/parisagreement-model-for-global-governance-by-anne-marie-slaughter-201512 ?barrier=accesspaylog

Starkey, R., \& Zhang, C. (2011). Assessing common(s) arguments for an equal per capita allocation. The Geographical Journal, 177(2), 112-126. doi: 10.1111/j.14754959.2010.00359.x 
Steininger, K. W., Lininger, C., Meyer, L. H., Munoz, P., \& Schinko, T. (2016). Multiple carbon accounting to support just and effective climate policies. Nature Climate Change, 6, 35-41. doi: 10.1038/nclimate2867

Teixidó-Figueras, J., Steinberger, J. K., Krausmann, F., Haberl, H., Wiedmann, T., Peters, G. P., ... Kastner, T. (2016). International inequality of environmental pressures: Decomposition and comparative analysis. Ecological Indicators, 62, 163173. doi: 10.1016/j.ecolind.2015.11.041

Teng, F., He, J., Pan, X., \& Zhang, C. (2011). Metric of carbon equity: Carbon Gini Index based on historical cumulative emission per capita. Advances in Climate Change Research, 2, 134-140. doi: 10.3724/SP.J.1248.2011.00134

UNEP. (2017). The emissions gap report 2017. Nairobi: United Nations Environment Programme (UNEP).

United Nations. (1992). United Nations Framework Convention on Climate Change (UNFCCC).

United Nations Framework Convention on Climate Change (UNFCCC). (1997). Kyoto protocol. Kyoto:

United Nations Framework Convention on Climate Change (UNFCCC). (2014). Lima call for climate action. Lima:

United Nations Framework Convention on Climate Change (UNFCCC). (2015a). Paris agreement. Paris:

United Nations Framework Convention on Climate Change (UNFCCC). (2015b). Synthesis report on the aggregate effect of the intended nationally determined contributions. Paris:

United Nations Framework Convention on Climate Change (UNFCCC). (2018). Key messages from the Ministerial Talanoas. UNFCCC. Retrieved from https://talanoadialogue.com/ministerial-talanoas-old

United Nations General Assembly (UN GA). (2015). Transforming our world: The 2030 agenda for sustainable development. In UN (Ed.), A/RES/70/1. New York.

Victor, D. G. (2007). Fragmented carbon markets and reluctant nations: Implications for the design of effective architectures. Architectures for Agreement: Addressing Global Climate Change in the Post-Kyoto World, 133-160. doi:10.1017/CBO9780511802027.005

Vinod, T., Wang, Y., \& Fan, X. (1999). Measuring education inequality: Gini coefficients of education. The World Bank.

Voigt, C., \& Ferreira, F. (2016). Differentiation in the Paris Agreement. Climate Law, 6, 58-74. doi: 10.1163/18786561-00601004

Williams, A., \& Cookson, R. (2000). Equity in health. In A. J. Culyer \& J. P. Newhouse (Eds.), Handbook of health economics (Vol. 1, pp. 1863-1910). Amsterdam: Elsevier Science.

Winkler, H., Höhne, N., Cunliffe, G., Kuramochi, T., April, A., \& de Villafranca Casas, M. J. (2018). Countries start to explain how their climate contributions are fair: More rigour needed. International Environmental Agreements: Politics, Law and Economics, 18, 99-115. doi: 10.1007/s10784-017-9381-x 